\title{
Stage I Chronic Lymphocytic Leukemia
}

National Cancer Institute

\section{Source}

National Cancer Institute. Stage I Chronic Lymphocytic Leukemia. NCI Thesaurus. Code C7874.

Risk: Intermediate; Findings: Lymphocytosis and adenopathy; Survival (months): 95. (from AJCC 8th Ed.) 